\title{
Egg Productive Performance, Serum Lipid Profile and Economic Efficiency of Laying Hen Fed Different Levels of Cinnamon Oil Supplemented Diet
}

\section{Hanaa Mohamed Ghanem ${ }^{1 *}$, Rania El Sayed Mahmoud ${ }^{2}$,Hossam El-Shahat Gadalla ${ }^{3}$, Samer SAMIR IBRAHIM ${ }^{1}$}

${ }^{1}$ Department of Animal Husbandry and Wealth Development, Faculty of Veterinary Medicine, Mansoura University, Egypt; ${ }^{2}$ Department of Nutrition and Nutritional Deficiency Diseases, Faculty of Veterinary Medicine, Mansoura University, Egypt; ${ }^{3}$ Department of Clinical Pathology, Faculty of Veterinary Medicine, Mansoura University, Mansoura 35516, Egypt.

\begin{abstract}
The scope of the current work was to evaluate the potential effect of using different levels of cinnamon oil on performance, egg production, quality, serum lipid profile and egg yolk analyses in laying hens. A total of 160 Lohman Brown laying hen were randomly allocated into four treatments, each treatment was randomly allotted to four subgroups of birds each as a replicate. Laying hens in control group fed basal diet without any additives where as in the other treatments, hens fed diet supplemented with cinnamon essential oil at 50,100 and $150 \mathrm{mg} / \mathrm{kg}$ diet, respectively as T1, T2 and T3. Data (egg productive performance, egg quality, serum lipid profile, sensory meat characters, moisture, total solids and economic efficiency of laying hens) were analyze using General Linear Model procedure of the Statistical Analysis System package (SAS, 2002). Results revealed that egg productive performance and quality parameters were higher in all groups which received cinnamon essential oil (CEO). Serum lipid profile analyses revealed a significant increase in concentration of cholesterol in all treated groups than control group with a higher increase in T2 and T3 than T1. Triglycerides and HDL parameters show a significant decrease $(\mathrm{p}<0.05)$ in their levels in T2 and T3 more than T1. However, LDL value show a significant increase in T2 and T3 groups in compare to control group. It is concluded that dietary addition of cinnamon essential oil had Positive effect and improve the laying hen performance, egg quality and consequently the economic efficiency and $150 \mathrm{mg} / \mathrm{kg}$ is more efficient for this purpose.
\end{abstract}

Keywords | Egg production, Cinnamon oil, Growth, Economic income, Laying hen

Received | June 03, 2021; Accepted | June 24, 2021; Published | October 01, 2021

${ }^{*}$ Correspondence | Hanaa Mohamed Ghanem, Department of Animal Husbandry and Wealth Development, Faculty of Veterinary Medicine, Mansoura University, Egypt; Email: moody_henno@yahoo.com

Citation | Ghanem HM, Mahmoud RES, Gadalla HES, Ibrahim SS (2021). Egg productive performance, serum lipid profile and economic efficiency of laying hen fed different levels of cinnamon oil supplemented diet. Adv. Anim. Vet. Sci. 9(12): 2014-2020.

DOI | http://dx.doi.org/10.17582/journal.aavs/2021/9.12.2014.2020

ISSN (Online) | 2307-8316; ISSN (Print) | 2309-3331

Copyright (C) 2021 Ghanem et al. This is an open access article distributed under the Creative Commons Attribution License, which permits unrestricted use, distribution, and reproduction in any medium, provided the original work is properly cited.

\section{INTRODUCTION}

$\mathrm{T}$ The poultry industry is one of the main productive goals in the world as it impacts on the economic income and it has an important role in human nutrition and prevention of unemployment, (Reda et al., 2019). Egg production in the world has increased more than $50 \%$ in less than 2 decades (FAOSTAT, 2019), egg has been considered as a nutritious and affordable protein source.
Recently, the uses of antibiotics has been restricted for the growing concerns due to the presence of antibiotic resistant bacteria and transfer the residues of antibiotics in meat and eggs which may cause side-effects in human and many countries have banned the use of antibiotics (Isabel and Santos, 2009). Therefore, it is important to use alternatives to antibiotic feed additives in diets. Plant extracts, as one choice for the replacement of antibiotics have already been used in livestock feeds for keeping healthy due to have 
active components like essential oils (Wallace et al., 2010). Cinnamon is a spice which can be used as feed additive in poultry, cinnamaldehyde is the important component of cinnamon, creating about 65 percent of the extracted essential oil and these extracts significantly prevent fatty acid oxidation, lipid per oxidation and antioxidant properties in vitro, (Vali et al.,2013). Therefore, the objective of this study was to investigate the potential effects of using different levels of cinnamon oil supplemented diet on performance, egg production, egg quality, serum lipid profile, sensory characters, moisture, total solids and economic efficiency of laying hens.

\section{MATERIALS AND METHODS}

\section{ETHICS APPROVAL}

This study protocol was approved by the committee of animal welfare and ethics, Faculty of Veterinary Medicine, Mansoura University.

\section{EXPERIMENTAL BIRDS AND MANAGEMENT}

One hundred and sixty (24-wks. Old) laying hens (Lohman Brown) were randomly assigned to four treatments (Control, T1, T2 T3) 40 birds each, then each treatment was further randomly allotted to four subgroups of birds each as a replicate. The feeding trial lasted for 90 days. The experimental diets were corn and soybean meal based with $0 \%$ cinnamon oil (control) (Table 1) and other experimental diets basal diet supplemented with cinnamon essential oil (CEO) at the concentrations of 50, 100 and $150 \mathrm{mg} / \mathrm{kg}$, respectively. All diets were iso-caloric and isonitrogenous. The experimental hens were maintained on lighting (16L: 8D) per day and on standard conditions of temperature and ventilation.

\section{EGG PRODUCTIVE PERFORMANCE}

Daily collection, count and weight of egg individually to the nearest $\mathrm{mg}$ were done and recorded for 12 weeks then prepared for egg quality parameters analysis which divided into external and internal egg quality. Regarding to external quality, fifteen eggs per each subgroup were selected at random weekly for egg quality analysis. Total egg number counted and egg mass/hen/week was calculated using the following formula:

\section{Egg Mass/hen $=$ Egg weight $\times$ Egg number.}

\section{INTERNAL EGG QUALITY}

Eggs were individually weighed, then broken and the inner contents were placed on a leveled glass surface to determine yolk and albumin grade. Egg shell, yolk and albumin were separated and weighed on a fresh matter basis; HU (Haugh unit) was determined according to the following equation: $\mathrm{HU}=100 \log \left(\mathrm{H}+7.57-1.7 \mathrm{~W}^{0.37}\right)($ Haugh, 1937).
Table 1: Ingredients and calculated composition of basal diet (as- fed).

\begin{tabular}{ll}
\hline Diet & Ingredients \% \\
\hline 61.6 & Yellow corn \\
\hline 22.4 & Soybean meal \\
\hline 4.6 & Corn gluten \\
0.9 & Mixed oil \\
\hline 9 & limestone \\
0.5 & Dicalcium phosphate \\
0.23 & Min.Vit. premix ${ }^{1 *}$ \\
0.3 & Salt \\
0.15 & Dl-methionine \\
0.3 & threonine \\
100 & Total \\
Calculated nutrient content ${ }^{2}$ & \\
\hline 18.03 & CP\% \\
2804.89 & ME $(\mathrm{kcal} / \mathrm{kg})$ \\
3.52 & Ca\% \\
\hline 0.43 & P\% \\
0.47 & Methionine\% \\
\hline 0.81 & Lysine\% \\
\hline
\end{tabular}

Vitamin-mineral premix provided per kilogram diet: IU: vit. A 8000 , vit. $\mathrm{D}_{3} 1300$; mg: vit. $\mathrm{E} 5$, vit. $\mathrm{K} 2$, vit. $\mathrm{B}_{1} 0.7$, vit. $\mathrm{B}_{6} 3$, vit. $\mathrm{B}_{6} 1.5$, vit. $\mathrm{B}_{2} 7$, biotin 0.1 , folic acid 1 , pantothenic acid 6 , niacin 20, Mn 60, Zn 50, Cu 6, I1,Se 0.5,Co1; ${ }^{2}$ calculated according to NRC (1994).

Yolk height was measured in mm using a tripod $\mu \mathrm{m}$, yolk width was measured in mm using a vernier caliper and yolk index was calculated from the equation:

\section{Yolk index $=$ Yolk height Yolk diameter}

Egg shells were rinsed clean with distilled water and dried in an oven before weighing and measurement of thickness twice on opposite sides of the midline with a digital micrometer. All egg quality measurements were performed by the same person throughout the study to prevent any subjective influence.

Hen production performance was quantified by calculating hen day egg production (EP, \%), average egg weight (EW, $\mathrm{g} / \mathrm{egg}$ ), hen day egg mass (EM, g/hen/day), average daily feed intake (ADFI, g/hen/day), and feed conversion ratio (FCR, $\mathrm{g}$ feed/g egg laid).

\section{EXPERIMENTAL SAMPLES}

Percent of moisture, total solids and total lipids OF EGG YOLK

At the end of the experimental period, ten eggs from each replicate were collected and the yolks separated from the whites. The yolks were then pooled and stored 
at $-20{ }^{\circ} \mathrm{C}$ until analysis. Moisture content of egg yolks was determined as described by (AOAC Association, 1990). Total yolk solids were calculated by the difference between 100 and the moisture content. Total lipids were determined gravimetrically by taken $1 \mathrm{ml}$ of lipid extract from egg yolk sample and put in aluminum foil, evaporated the chloroform by using heater, then weighed the residue and difference in the weight considered lipid \% according to (Cherian et al., 2002).

\section{Serum LiPID PROFILE}

At the end of feeding trial, five birds per replicate were randomly selected, weighed and slaughtered. Blood samples were collected, serum separated and kept frozen for subsequent analysis. Serum total protein (TP) and albumin (Alb) were evaluated using Stanbio Laboratory USA kits according to (Dumas and Biggs, 1972). Cholesterol, triglycerides and high density lipoprotein HDL were assessed according to (Young and Friedman, 2001) using kits produced by Spinreact Spain.

\section{Sensory Meat Quality EVAlUation}

At the end of experiment five birds from each replicate were slaughtered as representative samples for sensory meat evaluation. Fresh coded breast muscle samples were cooked as home cooking. The cooked samples were cut into $1 \mathrm{~cm}$ slices, and the samples were served to a panel of members (10 numbers) selected from staff members and workers in the department of Food Health and Safety, Faculty of Veterinary Medicine, Mansoura University. They were provided with a scorecard of eight hedonic points to assess the color, appearance, flavor, texture, juiciness, tenderness, and overall acceptability of the meat.

\section{Economic evaluation parameters (Production COSTS AND RETURNS) \\ TOTAL FIXED COSTS (TFC)}

Include the rent of the building and depreciation of equipment. The depreciation rates were calculated on 5 years for the equipment and for the buildings on 25 years (Atallah, 2000).

\section{TOTAL VARIABLE COSTS (TVC)}

Include costs of drugs, vaccines, disinfectants, veterinary supervision, feed, chicks, labour, litter, electricity and miscellaneous costs, (Bano et al., 2011).

$$
\text { Total costs }(T C)=T V C+T F C
$$

\section{RETURNS}

The total return (TR) from total eggs sale that calculated according to the market prices during the study and the net return $(\mathrm{NR})=\mathrm{TR}-\mathrm{TC}$.
Economic efficiency $\%=\frac{\text { net return }(E G P)}{\text { total feed cost }(E G P)} X 100$

(Atallah et al., 1999)

\section{StATISTICAL ANALYSIS}

Association analysis; data were analyzed using the General Linear Model procedure of the Statistical Analysis System package (SAS, 2000). Preliminary test was applied to the percentage data before comparison and analysis, and found that data was homogeneous and did not need transformation to the corresponding arcsine angle. Preliminary test was also applied and found a non-significant effect of replicate. All data are expressed as the Least Square Mean (LSM) \pm S.E.

\section{RESULTS AND DISCUSSION}

First not the other, all birds reported in this trail still healthy and livable to the end of the experiment without any mortality.

The effects of using different levels of cinnamon oil supplemented diet on performance, egg production, egg quality, serum lipid profile, sensory characters, moisture, total solids and economic efficiency of laying hens.

\section{EGG PRODUCTION PERFORMANCE}

Egg production value was significantly higher in all treated groups received cinnamon essential oil (CEO) in diet compared to control group. Egg weight and egg mass significantly higher in group received $150 \mathrm{mg} / \mathrm{kg}$ from CEO compared to other experimental groups (Table 2). There were significant differences in feed conversion ratio between all experimental groups compared to control one and experimental group which received high level of cinnamon oil $(100,150 \mathrm{mg} / \mathrm{kg}$ from CEO) had the best FCR. Egg weight and mass were significantly higher in group received $150 \mathrm{mg} / \mathrm{kg}$. Supplementation of cinnamon essential oil (CEO) significantly increased the haugh unit, eggshell thickness and egg yolk index $(\mathrm{P}<0.05)$ in all experimental groups compared with control one (Table 3 ).

\section{LIPID PROFILE OF SERUM}

There were significant increases $(\mathrm{p}<0.05)$ in concentration of cholesterol in all treated groups than control group with a higher increase in T2 and T3 groups than T1 group. Triglycerides and HDL parameters show a significant decrease in their levels in T2 and T3 groups more than T1 group. However, LDL value show a significant increase in T2 and T3 groups in compare to control group. Total protein and albumin revealed non-significant changes between all treated groups with cinnamon oil and control group (Table 4). 
Table 2: Effect of dietary supplementation different levels of CEO on productive performance.

\begin{tabular}{|c|c|c|c|c|c|}
\hline \multirow[t]{2}{*}{ Traits } & \multicolumn{5}{|c|}{ Treatments } \\
\hline & $\mathrm{C}$ & $\mathrm{T} 1$ & $\mathrm{~T} 2$ & T3 & $P$ - value \\
\hline Egg weight (g) & $58.25^{c} \pm 0.47$ & $59.63^{b} \pm 0.50$ & $59.94^{b} \pm 0.49$ & $60.36^{a} \pm 0.53$ & 0.001 \\
\hline Egg production $\%$ & $87.50^{\mathrm{b}} \pm 0.50$ & $94.60^{\mathrm{ab}} \pm 0.51$ & $96.33^{\mathrm{a}} \pm 0.49$ & $96.92^{\mathrm{a}} \pm 0.48$ & 0.012 \\
\hline Egg mass & $50.97^{c} \pm 0.65$ & $56.41^{\mathrm{b}} \pm 0.61$ & $57.74^{\mathrm{ab}} \pm 0.54$ & $58.51^{\mathrm{a}} \pm 0.61$ & 0.001 \\
\hline $\mathrm{FI} \mathrm{g/h/d}$ & $103.45 \pm 0.43$ & $103.22 \pm 0.41$ & $103.17 \pm 0.41$ & $103.01 \pm 0.41$ & 0.523 \\
\hline FCR (intake/egg laid) & $2.03^{a} \pm 0.41$ & $1.83^{b} \pm 0.41$ & $1.78^{c} \pm 0.52$ & $1.76^{c} \pm 0.54$ & 0.01 \\
\hline
\end{tabular}

FI (feed intake), FCR (feed conversion ratio). Means bearing different superscripts in a row differ significantly $(\mathrm{P}<0.05)$.

Table 3: Effect of dietary supplementation different levels of CEO on egg quality parameters.

\begin{tabular}{lllllll} 
Traits & \multicolumn{3}{c}{ Treatments } & T3 & Pvalue \\
& C & T1 & T2 & $87.96^{\mathrm{ab} \pm 0.58}$ & $88.7^{\mathrm{a}} \pm 0.60$ & 0.01 \\
HU & $76.30^{\mathrm{c}} \pm 0.49$ & $86.61^{\mathrm{b}} \pm 0.52$ & $0.43^{\mathrm{a}} \pm 0.41$ & $0.43^{\mathrm{a}} \pm 0.48$ & 0.05 \\
Yolk index & $0.40^{\mathrm{b}} \pm 0.52$ & $0.43^{\mathrm{a}} \pm 0.49$ & $0.35^{\mathrm{a}} \pm 0.41$ & $0.36^{\mathrm{a}} \pm 0.38$ & 0.05
\end{tabular}

Means bearing different superscripts in a row differ significantly $(\mathrm{P}<0.05)$.

Table 4: Effect of supplementation different levels of CEO on serum lipid profile.

\begin{tabular}{lllll} 
Traits & \multicolumn{4}{c}{ Treatments } \\
Cholesterol & $\mathrm{C}$ & $\mathrm{T} 1$ & $\mathrm{~T} 2$ & T3 \\
Triglycerides & $149^{\mathrm{d}} \pm 2.6$ & $156^{\mathrm{c}} \pm 1.5$ & $174.33^{\mathrm{b}} \pm 2.6$ & $194.33^{\mathrm{a}} \pm 2.6$ \\
HDL & $72.66^{\mathrm{a}} \pm 1.7$ & $71^{\mathrm{a}} \pm 1.15$ & $61.66^{\mathrm{b}} \pm 3.2$ & $62^{\mathrm{b}} \pm 1.7^{2}$ \\
LDL & $58.33^{\mathrm{a}} \pm 1.4$ & $55.33^{\mathrm{a}} \pm 1.8$ & $45^{\mathrm{b}} \pm 1.2$ & $46^{\mathrm{b}} \pm 1.9$ \\
Total protein & $18.66^{\mathrm{c}} \pm 2.5$ & $33.66^{\mathrm{b}} \pm 1.7$ & $41.66^{\mathrm{a}} \pm 2.1$ & $44.33^{\mathrm{a}} \pm 1.9$ \\
Albumen & $3.3^{\mathrm{a}} \pm 0.17$ & $3.1^{\mathrm{a}} \pm 0.035$ & $3.4^{\mathrm{a}} \pm 0.2$ & $3.3^{\mathrm{a}} \pm 0.38$ \\
\hline
\end{tabular}

Means bearing different superscripts in a row differ significantly $(\mathrm{P}<0.05)$.

\section{EGG YOLK ANALYSES}

There were no significant differences in moisture and total solids content of egg yolk with the addition of CEO by different levels (Table 5), while there were significant differences in total lipid \% between all experimental groups and T3 had the highest numerically lipid \% in egg yolk.

\section{SENSORY MEAT EVALUATION}

Namely appearance, flavor, texture, juiciness, mouth coating, and overall acceptability are presented in Table 6. In this study, sensory evaluation of meat was not influenced by supplementation of $\mathrm{CEO}$ at different levels.

\section{ECONOMIC EVALUATION PARAMETERS}

Results in Table 7 showed that, there is a significant difference $(\mathrm{P}<0.01)$ among the different treated groups in the values of TVC and TC. The TVC and TC with the higher levels in treatment $3(150 \mathrm{mg}$ from COE $/ \mathrm{kg}$ diet) and treatment 2 (100 $\mathrm{mg}$ from CE/ $\mathrm{kg}$ from diet). Whereas, the lowest total variable costs and total costs observed in control group. These differences in total variable costs attributed mainly to the changes in costs of feed manufacturing not to the amount of feed consumed, as the highest costs of manufacturing were recorded for T3 followed by T2, T1 and the lowest manufacturing cost were in control group. The differences in TC values among the groups are accordingly the same as the TVC where, the highest value in T3 and the lowest in control group. These results may be attributed to the effect of feed costs on the TVC and TC, which represents about $70 \%$ of the production costs in poultry farms. Regards to total return and net return values cleared that the dietary treatment with cinnamon oil resulted in a positive effect of increasing the total returns and net returns when compared to control group. The higher values of total return were 961 EGP and 956 EGP in treatment 3 and treatment 2, respectively. Meanwhile, lowest total return value were 868 EGP recorded in control group. Unlike that of TR the results of NR showed that the highest values were 150.32 EGP in treatment 1 followed by 148.61 EGP in treatment 2 , while the lowest value 130.86 EGP observed in control group. This difference between TR and NR results is owed to that calculation of total returns depends on sales of total number of eggs or EP\% for each group and includes in its calculation the total costs of production, but NR is a net revenue or profit after subtracting the production costs. 
Table 5: Composition of egg yolk of laying hens fed diets with different levels of CEO.

\begin{tabular}{lllll} 
Traits & \multicolumn{4}{c}{ Treatments } \\
& C & T1 & T2 & T3 \\
Moisture )\%) & $52.43 \pm 0.58$ & $49.63 \pm 0.52$ & $50.10 \pm 0.47$ & $50.41 \pm 0.61$ \\
Total solid (\%) & $47.56 \pm 0.58$ & $50.36 \pm 0.25$ & $49.90 \pm 0.13$ & $49.59 \pm 0.61$ \\
Total Lipid (\%) & $9.00^{\mathrm{ab}} \pm 0.59$ & $9.70^{\mathrm{ab}} \pm 0.17$ & $7.6^{\mathrm{b}} \pm 0.14$ & $14.6^{\mathrm{a}} \pm 0.15$
\end{tabular}

Means bearing different superscripts in a row differ significantly $(\mathrm{P}<0.05)$.

Table 6: The effect of supplementation of CEO on the sensory evaluation of meat Quality.

\begin{tabular}{llllll} 
Traits & \multicolumn{5}{c}{ Treatments } \\
& C & T1 & T2 & T3 & Pvalue \\
Appearance & $6.41 \pm 0.11$ & $6.36 \pm 0.21$ & $6.21 \pm 0.10$ & $6.11 \pm 0.22$ & 0.245 \\
Texture & $6.19 \pm 0.23$ & $6.28 \pm 0.21$ & $6.26 \pm 0.22$ & $6.24 \pm 0.23$ & 0.313 \\
Color & $6.17 \pm 0.22$ & $6.34 \pm 0.19$ & $6.27 \pm 0.11$ & $6.11 \pm 0.18$ & 0.435 \\
Juiciness & $6.21 \pm 0.20$ & $6.23 \pm 0.30$ & $6.47 \pm 0.28$ & $6.31 \pm 0.22$ & 0.564 \\
Flavour & $6.86 \pm 0.22$ & $6.36 \pm 0.19$ & $6.58 \pm 0.33$ & $6.42 \pm 0.20$ & 0.345 \\
Overall acceptability & $6.04 \pm 0.22$ & $6.08 \pm 0.17$ & $6.05 \pm 0.20$ & $6.03 \pm 0.23$ & 0.416
\end{tabular}

Means bearing different superscripts in a row differ significantly $(\mathrm{P}<0.05)$.

Table 7: Total variable cost (TVC), total fixed cost (TFC), total cost (TC), total return (TR) and net return (NR) among treated groups.

$\begin{array}{lllllll}\text { Group } & \text { TVC (EGP) } & \text { TFC (EGP) } & \text { TC (EGP) } & \text { TR (EGP) } & \text { NR (EGP) } & \text { Economic efficiency \% } \\ \text { C } & 715.14 \pm 2.80 & 22 & 737.14 \pm 2.79 & 868 \pm 4.25 & 130.86 \pm 1.67 & 0.23 \\ \text { T1 } & 765.68 \pm 3.11 & 22 & 787.68 \pm 3.11 & 938 \pm 3.75 & 150.32 \pm 0.98 & 0.25 \\ \text { T2 } & 785.39 \pm 2.85 & 22 & 807.39 \pm 2.84 & 956 \pm 3.17 & 148.61 \pm 1.47 & 0.24 \\ \text { T3 } & 805.56 \pm 1.94 & 22 & 827.56 \pm 1.95 & 961 \pm 3.82 & 133.44 \pm 1.93 & 0.21\end{array}$

Means bearing different superscripts in a row differ significantly $(\mathrm{P}<0.05)$.

In regards to the economic efficiency, from the economical point of view, feeding layer on T1 diet gave the best economic efficiency value (25\%) followed by T2 diet gave $(24 \%)$, whereas the lowest efficiency value was in T3 diet gave (21\%) followed by control one gave (23\%). The present study illustrated that although the addition of cinnamon oil in layer diets will improve the returns (TR and NR) when compared to the control due to the increase in total egg number in the treated groups but the economic efficiency revealed that the best concentrates of cinnamon oil to be used in layer diets is (50) in T1 diet and (100) in T2 diet.

Dietary supplementation of cinnamon oil in laying hens improved feed conversion ratio, egg production, egg weight and mass; while FI not affected. In the present study dietary cinnamon oil addition at greater concentrations (150 $\mathrm{mg} / \mathrm{kg}$ ) improved the laying performance and this may be explained as cinnamon is rich in iron, zinc, chromium, manganese, calcium, magnesium, potassium and phosphorus. These minerals have positive effects on reproductive performance and egg production of laying. Regarding feed intake, cinnamon oil supplementation did not affect on feed intake considering the properties of the organic acids that they contain. In this regard, it has been stated that due to time of dissociation, organic acids have a superior bactericidal capacity than HCL which is a strong acid and its dissociation happens more quickly than weak organic acid. Our results were in-agreements with (Torki et al.,2015) who found that cinnamon oil supplementation to hens has beneficial effect on FCR. Additionally, (Simsek et al., 2015) found that cinnamon essential oil supplementation into a diet of laying quails with a 200 ppm level increased egg production and improved the feed conversion ratio. Moreover, (Pakiza et al., 2020) concluded that cinnamon oil contains some volatile oils in addition to saturated and unsaturated fatty acids which have a positive impact on egg production and FCR which may be the cause of improving laying performance associated with cinnamon oil supplementation. Similarly, to our results, (Mahmoud et al., 2020) found that the egg mass was significantly higher in group received $300 \mathrm{mg} / \mathrm{kg}$ from cinnamon oil than in the control group. Hen-day egg production, quality and shell thickness were significantly improved at 58 to 61 weeks with the diet supplemented with essential oils, (Ding et al., 2017). On the contrary, (Cufadar, 2018) reported that egg weight, mass and quality were not affected by the diet supplemented with essential 
oils. Dissimilarly, (Ali et al., 2007) found that there was no change in the yolk index, shell thickness and Haugh units due to addition of $0.25 \%$ thyme in the diet of laying hens.

Lipid profile of serum analyses revealed a significant increase in concentration of cholesterol in all treated groups than control group with a higher increase in T2 and T3 groups than T1 group. Triglycerides and HDL parameters show a significant decrease in their levels in T2 and T3 groups more than T1 and control groups. However, LDL value show a significant increase in T2 and T3 groups in compare to control group. All data obtained in our study show the beneficial effect of CEO on HDL, LDL and triglycerides in serum of laying hens with egg productivity and egg quality. So, the increase in cholesterol level usually contributed to addition of different oil emulsion to the diet of laying hens. Herkel et al. (2016) found that triglycerides, cholesterol concentration of blood of hens increased $(\mathrm{P}<0.05)$ after oil inclusion. Conversely, (Abo Ghanima et al., 2020) revealed a significant decrease in cholesterol level after addition of cinnamon and rosemary to layer hens. However, LDL value show a significant increase in T2 and $\mathrm{T} 3$ groups in compare to control group. Marcos et al. (2019) found a higher increase in serum triglycerides level on day 84 in hens that received $200 \mathrm{mg}$ of orange essential oil per $\mathrm{kg}$ of feed has a negative effect on their health. (Gumus et al., 2017), found that a significant decrease in the serum LDL levels of the groups receiving 150 and 450 $\mathrm{mg} / \mathrm{kg}$ of thyme essential oil in diet. Bastos et al. (2017) found that quails fed with cinnamon supplementation also had a higher triglyceride and VLDL contents.

Serum total protein and albumin in our results revealed a non-significant changes between control and all treated groups with cinnamon oil, which go parallel with (Abo Ghanima et al., 2020) after addition of cinnamon and rosemary to layer hens.

There were no significant differences in moisture and total solid content of egg yolk with the addition of different levels of CEO. The present findings were agreement with (Vidal et al., 2013) who reported that there were no significant differences in moisture and total solids content of yolk with addition of cashew nut meal to the diet of laying hens. The group of hens which received $150 \mathrm{mg}$ from CEO had the highest numerically lipid percent in egg yolk.

\section{SENSORY MEAT EVALUATION}

The supplementation of cinnamon essential oil supplemented diet (CEO) (T1, T2, and T3) had nonsignificant effect on the sensory evaluation of meat parameters. These findings were similar to that obtained by (Chowlu et al., 2019) who showed that sensory evaluation (the organoleptic evaluation of meat viz. appearance, tender, colour and juiciness) of broiler chicken meat fed supplemented diet with different levels of cinnamon oil were unaffected irrespective of treatment. Moreover, (Gomathi et al., 2018) stated that all parameters of sensory evaluation of meat were found to be comparable between the treatment groups. On the contrary, the cinnamon powder at $5 \%$ increased the taste and flavor of broiler meat (Sang-Oh et al., 2013).

\section{CONCLUSIONS AND RECOMMENDATIONS}

It may be said that, laying hen fed cinnamon essential oil supplemented diet revealed higher egg productive performance and quality without any effects on meat quality. From the economic point of view, treatment group receive $50-100 \mathrm{mg} / \mathrm{kg}$ were the best. In the near future, it is expected that essential oils will play a huge role in the poultry industry development.

\section{ACKNOWLEDGMENTS}

The authors acknowledge Dr. Eman Manaa, Assistant Proffessor of Animal Production, Faculty of Veterinary Medicine, Banha University for his kind cooperation. Also, many cardinal thanks for all members of Food Health and Safety Program, Faculty of Veterinary Medicine, Mansoura University for their valuable advices.

\section{NOVELTY STATEMENT}

Using of cinnamon oil with different levels $(50,100,150$ $\mathrm{mg} / \mathrm{kg}$ diet) not recorded in laying hen later, especially with calculation of economic effeciency and the serum lipid profile of treated laying hen.

\section{AUTHOR'S CONTRIBUTION}

The authors acknowledge all members of Food Health and Safety Program, Faculty of Veterinary Medicine, Mansoura University for their valuable advices and kind cooperation.

\section{CONFLICT OF INTEREST}

The authors have declared no conflict of interest.

\section{REFERENCES}

-AOAC (1990). Association of official Analytical Chemists, Official Methods of Analysis. 15 ${ }^{\text {th }}$ Edition, Washington, D.C, USA.

- Abo Ghanima MM, Elsadek MF, Taha AE, Abd El-Hack ME, Alagawany M, Ahmed BM, Elshafie MM, ElSabrout K (2020). Effect of Housing system and rosemary and cinnamon essential oils on layers performance, egg quality, hematological traits, blood chemistry, immunity, and antioxidant. Animals, 10: 245. https://doi.org/10.3390/ ani10020245 
-Ali MN, Hassan MS, El-Ghany FA (2007). Effect of strain, type of natural antioxidant and sulphate ion on productive, physiological and hatching performance of native laying hens. Int.J. of Poul. Sci., 6: 539-554. https://doi.org/10.3923/ ijps.2007.539.554

-Atallah ST (2000). Study the economic and productive efficiency of some broiler farms in relation to ration constituents. Minoufyia Vet. J., pp. 169-183.

-Atallah ST, Khalil RH, Nadia BM (1999). Economic losses due to fish diseases at the farm level. Alex. J. Vet. Sci., 15(2): 181-194.

-Bano R, Shah H, Sharif M, Akhtar W (2011). Profitability index and capital turn over in open house broiler farming: A case study of district Rawalpindi. Pak. J. Agric. Res., 24(14): $75-81$.

- Bastos MS, Del Vesco AP, Santana TP, Santos TS, de Oliveira Junior GM, Fernandes RPM (2017). The role of cinnamon as a modulator of the expression of genes related to antioxidant activity and lipid metabolism of laying quails. PLoS One, 12: e0189619. https://doi.org/10.1371/journal. pone.0189619

- Cherian G, Selvaraj RK, Goeger MP, Stitt AP (2002). Muscle fatty acid composition and thiobarbituric acid- reactive substances of broilers fed different cultivars of sorghum. Poult. Sci., 81: 1415-1420. https://doi.org/10.1093/ ps/81.9.1415

- Chowlu H, Vidyarthi K, Zuyie R, Maiti CS (2019). Use of cinnamon in diet of broiler chicken. A review. Livest. Res. Int., 6: 42-47.

- Cufadar YE (2018). Effects of dietary different levels of rosemary essential oil on performance and eggshell quality parameters in laying hens. Selcuk. J. Agric. Food Sci., 32: 454-457. https://doi.org/10.15316/SJAFS.2018.122

-Ding X, Yu Y, Su Z, Zhang KE (2017). Effects of essential oils on performance, egg quality, nutrient digestibility and yolk fatty acid profile in laying hens. Anim. Nutr. 3: 127-131. https://doi.org/10.1016/j.aninu.2017.03.005

-Dumas BT, Biggs HG (1972). I.N. Standard Methods of clinical chemistry, Academic press, New York, USA.

-FAO STAT, 2019. Livestock primary. Available at: http://www. fao.org/faostat/en/\#data/QL

- Gomathi G, Senthilkumar S, Amirthalingam Natarajan A, Ramasamy Amutha R, Purushothaman M (2018). Effect of dietary supplementation of cinnamon oil and sodium butyrate on carcass characteristics and meat quality of broiler chicken. Vet. World, pp. 11. https://doi.org/10.14202/ vetworld.2018.959-964

- Gumus R, Ercan N, Imik H (2017). The effect of thyme essential oil (Thymus Vulgaris) added to quail diets on performance, some blood parameters, and the antioxidative metabolism of the serum and liver tissues. Revista Brasileira de Ciência Avícola, 19: 297-304. https://doi.org/10.1590/1806-90612016-0403

- Haugh RP (1937). Haugh unites for measuring egg quality. Poult. Mag., 43: 552.

- Herkel K, Galik B, Biro D, Michal Rolinec M, Simko M, Juracek M, Arpasova H, Hanusovsky O (2016). The effect of essential oils on mineral composition of egg mass and blood parameters of laying hens. J. Central Eur. Agric., 17: 1150-1167. https://doi.org/10.5513/JCEA01/17.4.1824

-Isabel B, Santos Y (2009). Effects of dietary organic acids and essential oils on growth performance and carcass characteristics of broiler chickens. J. Appl. Poult. Res., 18:
472-476. https://doi.org/10.3382/japr.2008-00096

- Mahmoud MA, Mohamed FE, Ayman ET, Mohamed EA, Mahmoud A, Badreldin MA, Mona ME, Karim E (2020). Effect of housing system and rosemary and cinnamon essential oils on layers performance, egg quality, Hematological Traits, Blood Chemistry, Immunity, and Antioxidant. Animals, 10: 245. https://doi.org/10.3390/ ani10020245

- Marcos JM, Marcel MB, Lenilson FR, Mauricio B, AlessandraA, Weber SR, Alessandra CG, Gabriela MG, Gustavo M, Matheus DB, Roger W, Lenita CM, Aleksandro SD (2019). Oregano essential oil (Origanum vulgare) to feed laying hens and its effects on animal health. Anais da Academia Brasileira de Ciências, 91: e20170901. https://doi. org/10.1590/0001-3765201920170901

- Namra MMM, Wahed HMA, Fayek HM (2009). Evaluation of different sources of dietary zinc supplementation for Japanese quails, Laying performance. Egypt Poult. Sci., 29: 127-143.

-Pakiza H, Wasman M, Mahbuba AG (2020). The dietary impact of clove and cinnamon powders and oil supplementation on the performance, ileum morphology and intestine bacterial population of quails. Plant Arch., 20(1): 1503-1509.

-Reda FM, Alagawany M, Mahmoud HK, Mahgoub SA, Elnesr SS (2019). Use of red pepper oil in quail diets and its effect on performance, carcass measurements, intestinal microbiota, antioxidant indices, immunity and blood constituents. Animal, pp. 1-9. https://doi.org/10.1017/ S1751731119002891

-Sang-Oh P, Chae-Min R, Byung-Sung P, Jong H (2013). The meat quality and growth performance in broiler chickens fed diet with cinnamon powder. J. Environ. Biol., 34(1): 127-133.

- SAS (2000). SAS/STAT User's Guide. SAS Institute Inc., Cary, NC., USA.

- Simsek ÜG, Ciftci M, Özçelik M, Azman MA, Tonbak F, Özhan N (2015). Effects of cinnamon and rosemary oils on egg production, egg quality, hatchability traits and blood serum mineral contents in laying quails (Coturnixcoturnix Japonica). Ankara Üniv. Vet. Fak. Derg., 62: 229-236. https://doi.org/10.1501/Vetfak_0000002685

-Torki M, Akbari M, Kaviani K (2015). Single and combined effects of zinc and cinnamon essential oil in diet on productive performance, egg quality traits, and blood parameters of laying hens reared under cold stress condition. Int. J. Biometeorol., 59: 1169-1177. https://doi.org/10.1007/ s00484-014-0928-Z

-Vali N, Shahin H, Vatankhah M (2013). Determination of the effects of Cinnamomumzeylanicumblume and Thymus vulgaris on performance and egg quality of Japanese quail (Coturnix japonica). Res. Opin. A Vet. Sci., 3: 280-284. http://www.cibtech.org/cjz.htm

-Vidal TF, Pereira AF, Abreu VK, Freitas ER, Sousa MA, Zapata JF (2013). Egg quality and yolk lipid composition of laying. hens fed diets containing cashew nut meal. F. Sci. Technol. Campinas, 33: 172-179. https://doi.org/10.1590/S010120612013005000006

-Wallace RJ, Oleszek W, Franz C, Hahn I, Baser KH, Mathe A, Teichmann K (2010). Dietary plant bioactives for poultry health and productivity. Br. Poult. Sci., 51: 461-487. https:// doi.org/10.1080/00071668.2010.506908

-Young DS, Friedman RB (2001). Effect of disease on Clinical Lab Test ( ${ }^{\text {th }}$ Edn $)$ AACC, USA. 